\title{
Influence of Water Deficit on Photosynthetic Activity, Dry Matter Partitioning and Grain Yield of Different Durum and Bread Wheat Genotypes
}

\author{
T. AlLAhVERDiYeV ${ }^{1 *}$ and I. HuseYNOva ${ }^{2}$ \\ ${ }^{1}$ Research Institute of Crop Husbandry Ministry of Agriculture of Azerbaijan Republic, Baku, Azerbaijan \\ ${ }^{2}$ Institute of Molecular Biology and Biotechnology Azerbaijan National Academy of Sciences, \\ Baku, Azerbaijan \\ (Received 9 May 2016; Accepted 31 January 2017; \\ Communicated by T. Harangozó and A. Mohan)
}

\begin{abstract}
We aimed to study the influence of soil water deficit on gas exchange parameters, dry matter partitioning in leaves, stem and spike and grain yield of durum (Triticum durum Desf.) and bread (Triticum aestivum L.) wheat genotypes in the 2013-2014 and 2014-2015 growing seasons. Water stress caused reduction of stomatal conductance, photosynthesis rate, transpiration rate, an increase of intercellular $\mathrm{CO}_{2}$ concentration. Photosynthesis rate positively correlated with growth rate of genotypes. Drought stress caused adaptive changes in dry matter partitioning between leaves, stem and spike of wheat genotypes. Stem dry mass increased until kernel ripening. Drought stress accelerated dry mass reduction in leaves and stem. High growth rate of spike dry mass was revealed in genotypes with late heading time. Spike dry mass positively correlated with photosynthesis rate and grain yield. Generally, bread wheat is more productive and tolerant to drought stress than durum wheat.
\end{abstract}

Keywords: dry mass, gas exchange, grain yield, water deficit, wheat

Abbreviations: $\mathrm{g}_{\mathrm{s}}-$ stomatal conductance; $\mathrm{P}_{\mathrm{n}}-$ photosynthesis rate; $\mathrm{E}$ - transpiration rate; $\mathrm{C}_{\mathrm{i}}$ - intercellular $\mathrm{CO}_{2}$ concentration; $\mathrm{CGR}$ - crop growth rate

\section{Introduction}

Drought caused by lack of water in the soil is one of the main reasons for a decrease in wheat production worldwide. Water shortage in the soil is also accompanied with high temperature, low humidity and high irradiance after the heading stage of growth. Drought is the main cause reducing wheat productivity in rainfed regions of Azerbaijan. Drought stress may impair many plant functions, but the main effect is reduction of carbon fixation (Delfine et al. 2001). Reduced $\mathrm{CO}_{2}$ diffusion from the atmosphere to the site of carboxylation (decreased $\mathrm{g}_{\mathrm{s}}$ plus mesophyll conductance- $\mathrm{g}_{\mathrm{m}}$ ) is the main cause for decreased photosynthesis under most water-stress conditions (Flexas et al. 2004; Chaves et al. 2009; Peeva and Cornic 2009). When drought stress is prolonged, a general metabolic impairment can eventually occur, particularly under conditions of high light intensity that favors

\footnotetext{
*Corresponding author; E-mail: tofig_1968@mail.ru; Phone: +994504631989
} 
oxidative stress (Flexas et al. 2006; Zhou et al. 2007). Drought stress reduces photosynthetic characteristics, shortens the duration of photosynthesis and promotes the senescence of leaves (Liu et al. 2016). A decrease in $P_{n}$ limits expansion of assimilation area of vegetative organs and the accumulation of dry mass.

In addition to the leaves, photosynthetic active organs of wheat - all parts of the spike and the stem participate in $\mathrm{CO}_{2}$ assimilation in light (Wang et al. 2001). Stem and spike provide $40-50 \%$ of the required photosynthetic products during grain formation and filling (Evans and Rawson 1970; Araus et al. 1993). The importance of the total biomass in the improvement of productivity (Reynolds et al. 2007), especially under drought (Quarrie et al. 1999) was reported. Stem reserve utilisation was found to be an effective yieldsupporting mechanism under drought stress (Plaut et al. 2004). Plant productivity under drought stress is strongly related to the dry matter partitioning process (Kage et al. 2004), and the remobilization of pre-anthesis accumulate can be important for wheat yields (Ma et al. 2015). Although moderate drought at various growth stages can increase the amount and rate of pre-anthesis assimilate translocation, winter wheat grain yield is low under these conditions because dry matter accumulation decreases following anthesis (Liu et al. 2016). Drought stress not only limits the size of the source and sink tissues but the phloem loading, assimilate translocation and dry matter portioning are also impaired (Farooq et al. 2009).

The association of growth and grain yield with gas exchange characteristics of plants has not been clearly established (Ashraf and Harris 2013). Our aim was to study the effect of soil water deficit on leaf gas exchange parameters, dry mass dynamics in leaves, stem and spike and grain yield of durum (Triticum durum Desf.) and bread (Triticum aestivum L.) wheat genotypes. We also aimed to clarify the association of gas exchange parameters with growth and yield of wheat genotypes.

\section{Materials and Methods}

\section{Plant materials and growth condition}

The field experiment was conducted during the 2013-2014 and 2014-2015 growing seasons at the Research Institute of Crop Husbandry, located in the Absheron peninsula, Baku, Azerbaijan. Eight durum wheat genotypes (Garagylchyg 2,Vugar, Shiraslan 23, Barakatli 95, Alinja 84, Tartar, Sharg, Gyrmyzybugda), fourteen bread wheat genotypes (Nurlu 99, Gobustan, Akinchi 84, Giymatli 2/17, Gyrmyzy gul 1, Azamatli 95, Tale 38,

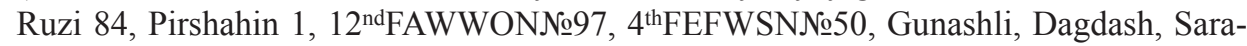
tovskaya 29) were employed in this study. Seeds of wheat genotypes were planted at the end of October, at an average density 400 seeds $\mathrm{m}^{-2}$ in three replications at $1 \mathrm{~m} \times 10 \mathrm{~m}$ plots, consisting of 7 rows placed $15 \mathrm{~cm}$ apart. Control plots were irrigated at germination, stem extension, and grain filling stages. Rainfed plots were not irrigated during ontogeny. 


\section{Gas exchange measurements}

The following gas exchange parameters were measured in flag leaf using LI-COR 6400XT Portable Photosynthesis System (LI-COR Biosciences, Lincoln, NE, USA): $\mathrm{P}_{\mathrm{n}}-$ net photosynthesis rate $\left(\mu \mathrm{mol} \mathrm{CO}_{2} \mathrm{~m}^{-2} \mathrm{~s}^{-1}\right), \mathrm{g}_{\mathrm{s}}$ - stomatal conductance $\left(\mathrm{mol} \mathrm{H}_{2} \mathrm{O} \mathrm{m}^{-2} \mathrm{~s}^{-1}\right)$, $\mathrm{C}_{\mathrm{i}}$ - intercellular $\mathrm{CO}_{2}$ concentration $\left(\mu \mathrm{mol} \mathrm{CO} \mathrm{CO}_{2}^{-1}\right), \mathrm{E}$ - transpiration rate $\left(\mathrm{mmol} \mathrm{H}_{2} \mathrm{O}\right.$ $\mathrm{m}^{-2} \mathrm{~s}^{-1}$ ). Measurements were made between 9:00 and 11:00 on days with full sunlight (1100-1500 $\mu \mathrm{mol} \mathrm{m} \mathrm{m}^{-2} \mathrm{~s}^{-1}$ photosynthetically active radiation). Data logging started after 45 seconds of insertion the leaf into chamber $\left(6 \mathrm{~cm}^{2}\right)$.

\section{Dry mass measurement}

The leaf, stem plus sheath and spike dry mass was measured after oven drying at $105^{\circ} \mathrm{C}$ for $24 \mathrm{~h}$. Crop Growth Rate (CGR) expresses the increase in biomass in a unit of area $\left(1 \mathrm{~m}^{2}\right)$ per a day, calculated as proposed by Hunt (1978). Mean values and standard deviations were calculated by Excel program. Correlation among traits was calculated by SPSS 16 software.

\section{Results}

\section{Gas exchange parameters}

Stomatal conductance, net photosynthesis rate and transpiration rate decreased significantly in flag leaves of genotypes in response to drought stress at anthesis. A decrease of stomatal conductance, net photosynthesis rate and transpiration rate amounted to an average $45 \%, 40 \%, 36 \%$ in the $2013-2014$ growing season, $42 \%, 43 \%, 38 \%$ in the $2014-2015$ growing season in sensitive genotypes Garagylchyg 2, Vugar, Barakatli 95, Alinja 84, Tartar, Nurlu 99, Gobustan, Akinchi 84, Giymatli 2/17, Azamatli 95, Tale 38, Ruzi 84, Pirshahin 1 (Table $\mathrm{S} 1 *$ ). A relatively less decrease of $\mathrm{g}_{\mathrm{s}}, \mathrm{P}_{\mathrm{n}}$ and $\mathrm{E}$ was revealed in genotypes Sharg, Gyrmyzy bugda, Gyrmyzy gul 1, Gunashli and Dagdash. The intercellular $\mathrm{CO}_{2}$ concentration in flag leaf of most genotypes increased under drought condition.

We found positive relationship between net photosynthesis rate and growth rate of genotypes (Fig. S1). This relationship indicates that higher photosynthesis rate allows rapid growth rate, greater accumulation of photoassimilates per unit of area.

\section{Leaf dry mass per stem}

The highest leaf dry mass per stem had Tartar among durum wheat genotypes and Giymatli 2/17 among bread wheat genotypes both in the 2013-2014 and in 2014-2015 growing seasons (Figs S2 and S3). Wheat genotypes Vugar, Alinja 84, Akinch 84,

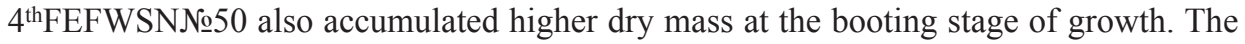
lowest dry mass of leaves was detected in genotype $12^{\text {nd }}$ FAWWON№97. Dry mass of

\footnotetext{
*Further details about the Electronic Supplementary Material (ESM) can be found at the end of the article.
} 
leaves reduced on average by $45 \%$ under irrigated, $61 \%$ under rainfed conditions from booting to kernel watery ripe stage in the 2013-2014 growing season, reduced by $75 \%$ under irrigated, $85 \%$ under rainfed conditions from booting to kernel dough ripe stage in the 2014-2015 growing season. Reduction in dry mass of leaves can be explained by translocation of photoassimilates to stem and spike and also by senescence of leaves, which is accelerated under water deficiency.

\section{Stem dry mass}

Stem dry mass of wheat genotypes increased until kernel ripening (Figs S4 and S5). An increase in dry mass of stem can be explained as an adaptation to decrease in the assimilation area and dry mass of leaves. The highest dry mass accumulation in the stem was detected in tall genotypes Sharg, Gyrmyzybugda, Dagdash and in Tartar, Akinchi 84, Giymatli2/17. The lowest dry mass of stem was detected in genotypes Gyrmyzy gul1 and

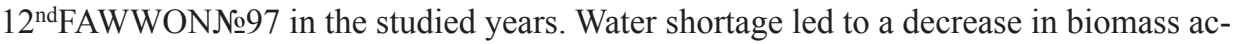
cumulation in the stem of studied wheat genotypes. Stem dry mass decreased on average by $22 \%$ under irrigation, $29 \%$ under rainfed condition from kernel watery ripe to kernel dough ripe in the 2013-2014 growing season. A decrease in stem dry mass from milky ripe to dough ripe amounted to average $37 \%$ under both irrigated and rain-fed conditions in the 2014-2015 growing season. The largest decrease in the dry mass of stem from milky ripe to dough ripe under irrigated and rain-fed conditions was revealed in genotypes Garagylchyg 2, Vugar, Shiraslan 23, Barakatli 95, Alinja 84, Nurlu 99, Akinchi 84, Giymatli 2/17, Gyrmyzy gul 1, Pirshahin 1, while lowest reduction in genotypes Dagdash, Saratovskaya 29 and Gyrmyzybuğda in the 2014-2015 growing season. Less reduction of stem dry mass is thought to be related to non-sufficient translocation of photoassimiliates to spike and decrease in harvest index value under terminal drought stress. The last three genotypes had the lowest harvest index in both 2013-2014 and 2014-2015 growing seasons.

\section{Spike dry mass}

Water shortage inhibited increase in dry mass of spike. The highest spike dry mass was detected in genotypes Tartar, Sharg under irrigated and rainfed conditions (Figs S6 and S7). Genotypic differences in the growth rate of dry mass of spikes was revealed. A high growth rate of spike dry mass from kernel watery ripe to kernel dough ripe under irrigated and rainfed conditions in the 2013-2014 and 2014-2015 growing seasons was revealed in genotypes Sharg (104\%, 92\% and 107\%, 92\%), Gyrmyzybugda (93\%, 50\% and $138 \%, 139 \%)$, Gyrmyzy gul $1(121 \%, 103 \%$ and $141 \%, 123 \%), 4^{\text {thFEFWSNNo50 }}$ (87\%, $57 \%$ and $111 \%, 79 \%)$, Dagdash $(130 \%, 94 \%$ and 148\%, 106\%) and Saratovskaya 29 $(152 \%, 98 \%$ and $174 \%, 140 \%)$. Reductions in dry mass of spike at kernel full ripe is more pronounced in the 2013-2014 growing season under water deficit. A significant reduction of spike mass under the influence of drought was found in genotypes Shiraslan 23, Barakatli 95, Tartar, Gyrmyzybugda, Akinchi 84, $12^{\text {nd }}$ FAWWON№97, $4^{\text {th }}$ FEFWSN№50 
in the 2013-2014 and in genotypes Nurlu 99, Gobustan, Akinchi 84, 12 ${ }^{\text {nd }}$ FAWWON№97 in the 2014-2015 growing seasons. Less decrease of spike mass was revealed in genotypes Sharg, Tale 38, Pirshahin 1, Gunashli, Dagdash and Saratovskaya 29.

\section{Grain yield}

The grian yield of the majority of genotypes was higher in the 2013-2014 growing season than that in the 2014-2015 growing season under irrigation (Fig. S8). However the grain yield of most genotypes was relatively higher in the 2014-2015 growing season under rainfed condition. A relatively strong decrease in grain yield of genotypes occurred in the 2013-2014 growing season. Reductions in grain yield were strongly expressed in genotypes Vugar, Barakatli 95, Alinja 84, Tartar, Tale 38, Akinchi 84 in the 2013-2014 grow-

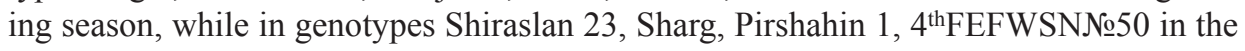
2014-2015 growing season. A slight decrease in grain yield in the studied years was found in genotypes Nurlu 99 and Saratovskaya 29. An average grain yield of durum and bread wheat genotypes was 588.6 and $670 \mathrm{~g} / \mathrm{m}^{2}$ under irrigation, 357.4 and $451.5 \mathrm{~g} / \mathrm{m}^{2}$ under rainfed condition in the 2013-2014 growing season. Reduction of grain yield was $39 \%$ for durum wheat genotypes, and $33 \%$ for bread wheat genotypes. Average grain yield of durum and bread wheat genotypes was 539.3 and $558.4 \mathrm{~g} / \mathrm{m}^{2}$ under irrigated, 382.8 and $443.2 \mathrm{~g} / \mathrm{m}^{2}$ under rainfed conditions in the 2014-2015 growing season, respectively. Reduction of grain yield constituted $29 \%$ for the durum wheat genotypes, $22 \%$ for the bread wheat genotypes. Genotypes Vugar, Shiraslan 23, Sharg, Gyrmyzybugda, Nurlu 99, Gobustan, Ruzi 84, 12 ${ }^{\text {nd }}$ FAWWON№97, Saratovskaya 29 formed stable grain yield under irrigated and rainfed conditions in the studied years. Potential productivity of genotypes Garagylchyg 2, Barakatli 95, Tartar, Giymatli 2/17, Gyrmyzy gul 1, Tale 38, Pirshahin 1, $4^{\text {th }}$ FEFWSN№50 were higher in the studied years.

\section{Correlations between studied traits}

Tables $\mathrm{S} 2$ and $\mathrm{S} 3$ show correlation coefficients between $\mathrm{P}_{\mathrm{n}}, \mathrm{g}_{\mathrm{s}}, \mathrm{E}$, leaf dry mass, stem dry mass, spike dry mass and grain yield under irrigated and rainfed conditions. While gas exchange parameters $\left(\mathrm{P}_{\mathrm{n}} \mathrm{g}_{\mathrm{s}}, \mathrm{E}\right)$ positively and significantly correlated with grain yield in the 2013-2014 growing season, correlation was negative in the 2014-2015 growing season. Spike dry mass positively and significantly correlated with leaf dry mass and stem dry mass under irrigated and rainfed conditions. Spike dry mass positively correlated with grain yield, but this correlation was not significant.

\section{Discussion}

Photosynthesis plays a pivotal role in grain yield, and nearly $70 \%$ of grain is derived from current photosynthesis in the leaves (Saeidi et al. 2012). High photosynthetic rate is considered to be one of the most important breeding strategies for crop improvement (Richards 2000). It is generally accepted that genotypes that are better able to sustain 
photosynthesis in the flag leaf for a longer time produce higher yields (Guoth et al. 2009). Genotypes with high gas exchange indices in flag leaf (Barakatli 95, Alinja 84, Tartar, Giymatli 2/17, Tale 38, Pirshahin 1, 4thFEFWSN№50) formed more dry biomass of leaves, stem and spike. In addition, genotypes with high gas exchange parameters (Gara-

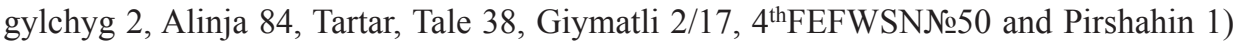
formed higher productivity. Genotypes with lower rate of photosynthesis (Gyrmyzy gul 1, 12 ${ }^{\text {nd}}$ FAWWONNo97, Saratovskaya 29) are characterized by lower assimilation area and dry mass. Despite the fact that wheat genotypes with high $\mathrm{P}_{\mathrm{n}}, \mathrm{g}_{\mathrm{s}}$ and $\mathrm{E}$ are more sensitive to drought, such advantage plays a role in stabilizing the productivity under drought. Higher photosynthesis rate, especially at the mid and later grain filling stages, promotes post-anthesis dry matter accumulation and grain filling (Man et al. 2015). A positive association of $\mathrm{P}_{\mathrm{n}}$ with growth rate of wheat genotypes was revealed. Murata (1981) found a positive relationship between potential leaf photosynthesis and maximal crop growth rate and potential biomass production. Water stress caused a reduction of $\mathrm{P}_{\mathrm{n}}, \mathrm{g}_{\mathrm{s}}$ and $\mathrm{E}$, an increase of $C_{i}$. Similar results were obtained in recent study of Liu et al. (2016). Although the decline in $P_{n}$ and $E$ occurred in response to decreased $g_{s}$, the $g_{s}$ was more closely related with $\mathrm{E}$ than $\mathrm{P}_{\mathrm{n}}$. Our results showed that $\mathrm{P}_{\mathrm{n}}$ is regulated both by $\mathrm{g}_{\mathrm{s}}$ and mesophyll conductance $\left(g_{m}\right.$, calculated from the ratio $\left.P_{n} / C_{i}\right)$, but $g_{m}$ plays a dominant role in the regulation of $\mathrm{P}_{\mathrm{n}}$ (Allahverdiyev et al. 2015). It is consistent with the findings of other authors (Siddique et al. 1999; Dulai et al. 2006; Olsovska et al. 2016). Green leaves of plants are the main source of products derived from photosynthesis (Kong et al. 2010). In general, durum wheat genotypes formed relatively large area of leaves per stem and accumulated more assimilates. However, a relatively high tillering capacity of bread wheat genotypes allowed an increase of leaf area index and accumulation of sufficient photoassimilates in unit of area. Our results showed that, assimilation area of leaves constitutes $64-87 \%$ of the total area depending on the genotype, the rest of the area accounted for stem at the booting stage. According to our results, flag leaf area constituted $74 \%$ under irrigation, $77 \%$ under rainfed of total leaf area at milky ripe stage. Flag leaf forms $75 \%$ of an effective leaf area for grain filling (Miller 1992). Flag and lower leaves have a significant share in ${ }^{14} \mathrm{C}$ accumulation in internodes, which indicate that leaves in the first place support carbohydrate collection before anthesis, for the development of early flowers (Griffith 1992). A positive and significant correlation of leaf dry mass with stem and spike dry mass indicate that leaves are main source of soluble carbohydrates. The largest dry mass of leaves per stem of wheat plant found in the booting stage, in the following growth stages (anthesis, kernel ripening) leaves in the lower layers gradually dries both in irrigation and rainfed conditions. However, the drought intensifies the senescence of leaves and dry mass further reduced due to increased respiration and translocation. The stem is an important assimilative organ, the main reserve of photosynthetic products transported to the spike during grain filling (Yang et al. 2001). Our results showed that, an increase in the assimilation area of stem continued until watery ripe, while an increase of dry mass continued until milky ripe. The accumulation of reserves in the stem begins from the formation of the first node continues until the beginning of grain filling (Berry et al. 2002). According to the reduction of dry mass of stem and increasing dry mass of spike 
from kernel watery ripe stage to kernel dough ripe stage it can be said that stem reserves has $10-50 \%$ share of increase in spike mass. Drought stress accelerated dry mass reduction in stem. The capacity of wheat genotypes to send more assimilates from stem into grain can be used as an important selection criteria. Translocation of stem reserves into grain was not sufficient in tall genotypes (Sharg, Gyrmyzybugda, Dagdash, Saratovskaya 29). Nor was there evidence that stem growth in tall cultivars was more likely to compete with grain growth (Rawson and Evans 1971). Spike is an important photosynthetic organ in green state, sink of photoassimilates is accumulated in leaves and stem. Our results showed that spike assimilation area constitutes $10.3 \%$ under irrigated, $10.8 \%$ under rainfed conditions during grain formation. Spike dry mass decreases under drought condition due to insufficiency of source. High growth rate of spike dry mass in some genotypes with late heading time can be explained by shortening the period of grain ripening. Bread wheat genotypes were superior to durum wheat genotypes for their yield and tolerance to drought stress. Our result is in agreement with result of Mekliche et al. (2015).

In the field conditions gas exchange parameters strongly dependent on the environmental factors (light intensity, air humidity, temperature, etc.). There was a positive correlation between gas exchange parameters and grain yield in the 2013-2014 growing season, while negative correlation was revealed in the 2014-2015 growing season. Grain yield negatively correlated with leaf dry mass and stem dry mass both in the 2013-2014 and 2014-2015 growing seasons. If compare, higher leaf dry mass, especially stem dry mass of wheat genotypes was formed in the 2014-2015 growing season than 2013-2014 growing season. In favorable conditions higher accumulation of photoassimilates in leaves, especially in stem compete with the outflow of photoassimilates to grains. Therefore, although the rate of photosynthesis was positively correlated with the accumulation of dry matter in the leaves and stem, negatively correlated with the grain yield in the 2014-2015 growing season. In our opinion continuing photosynthesis in flag leaf and spike in the postanthesis grain ripening stages play a significant role in the formation of grain yield. An enhanced grain yield of wheat is consistently associated with changes in photosynthetic characteristics, such as $P_{n}, T_{r}$ and $g_{s}$ of the flag leaf (Dahal et al. 2014). We detected positive significant correlations between grain yield and biological yield, spike number per $\mathrm{m}^{2}$, harvest index both under irrigated and rainfed conditions in the 20132014 growing season (Allahverdiyev 2016) and in the 2014-2015 growing season (unpublished results). Grain yield positively correlated with spike dry mass. Genotypic differences in biomass accumulation in leaves, stem, spike, as well as in the duration of the period of outflow of assimilates to the grain plays an important role in the formation of the grain yield. This process is significantly modified in adverse growing conditions. The relationship between grain yield and $\mathrm{P}_{\mathrm{n}}$ is not straight forward for a number of reasons (Reynolds et al. 2000). There are a number of physiological factors that reduce the amount of net carbon fixed which is then available for growth, principally respiration of assimilates during the dark period (Amthor 1989), as well as loss of carbon from root exudates, senescence and other processes. The absence of correlation between photosynthesis, individual photosynthetic parameters and grain yield is caused by biotic and abiotic factors 
whose limiting effect can be noticed during the phase of assimilate transport from the source (green photosynthetic organ) to the sink (spike, grain) (Sharkey et al. 1995).

As a conclusion, drought stress affects leaf gas exchange parameters, dry matter accumulation in different organs (leaf, stem and spike), grain yield of wheat. The decline in photosynthesis and transpiration rate occurred in response to decreased stomatal conductance. An increase in $\mathrm{C}_{\mathrm{i}}$ indicates non-stomatal limitation of photosynthesis at anthesis. Water stress inhibits accumulation of dry mass, accelerate senescence of leaves and biomass translocation. High photosynthesis rate is associated with high growth rate, can be used as a breeding strategy for wheat improvement. Adaptive changes in dry matter partitioning take place under drought stress. Water stress inhibits an increase of spike dry mass due to insufficient sources. Generally, bread wheat is more productive and tolerant to drought stress than durum wheat. Despite the fact that tall genotypes loses less yield under drought conditions, hence more resistant, translocation of stem reserves into grains is low in such genotypes, consequently the productivity decreases. Correlation between photosynthesis rate and grain yield not established strictly.

\section{References}

Allahverdiyev, T.I., Talai, J.M., Huseynova, I.M., Aliyev, J.A. 2015. Effect of drought stress on some physiological parameters, yield and yield components of durum (Triticum durum Desf.) and bread (Triticum aestivum L.) wheat genotypes. Ekin J. of Crop Breeding and Genetics 1:50-62.

Allahverdiyev, T. 2016. Yield and yield traits of durum wheat (Triticum durum Desf.) and bread wheat (Triticum aestivum L.) genotypes under drought stress. Genetika 48:717-727.

Amthor, J.S. 1989. Respiration and Crop Productivity. Springer-Verlag. Berlin, Germany.

Araus, J.L., Bort, J., Brown, R.H., Bassett, C.L., Cortadellas, N. 1993. Immunocytochemical localization of phosphoenolpyruvate carboxylase and photosynthetic gas-exchange characteristics in ears of Triticum durum Desf. Planta 191:507-514.

Ashraf, M., Harris, P.J.C. 2013. Photosynthesis under stressful environments: An overview. Photosynthetica 51:163-190.

Berry, P., Sylvester-Bradley, R., Philipps, L., Hatch, D.J., Cuttle, S.P., Rayns, F.W., Goslin, P. 2002. Is the productivity of organic farms restricted by the supply of available nitrogen? Soil Use Management 18:248255.

Chaves, M.M., Flexas, J., Pinheiro, C. 2009. Photosynthesis under drought and salt stress: regulation mechanisms from whole plant to cell. Ann. Bot. 103:551-560.

Dahal, K., Knowles, V.L., Plaxton, W.C., Hüner, N.P.A. 2014. Enhancement of photosynthetic performance, water use efficiency and grain yield during long-term growth under elevated $\mathrm{CO}_{2}$ in wheat and rye is growth temperature and cultivar dependent. Environ. Exp. Bot. 106:207-220.

Delfine, S., Loreto, F., Alvino, A. 2001. Drought stress effects on physiology, growth and biomass production of rainfed and irrigated bell pepper plants in the Mediterranean region. J. Am. Soc. for Horticult. Sci. 126:297-304.

Dulai, S., Molnar, I., Pronay, J., Csernak, A., Tarnai, R., Molnar-Lang, M. 2006. Effect of drought on photosynthetic parameters and heat stability of PSII in wheat and Aegilops species originated from dry habitats. Acta Biologica Szegediensis 50:11-17.

Evans, L., Rawson, H. 1970. Photosynthesis and respiration by the flag leaf and components of the ear during grain development in wheat. Aust. J. Biol. Sci. 23:245-254.

Farooq, M., Wahid, A., Kobayashi, N., Fujita, D., Basra, S.M.A. 2009. Plant drought stress: effects, mechanisms and management. Agron. for Sustainable Development 29:185-212. 
Flexas, J., Bota, J., Loreto, F., Cornic, G., Sharkey, T.D. 2004. Diffusive and metabolic limitations of photosynthesis under drought and salinity in $\mathrm{C}_{3}$ plants. Plant Biol. 6:269-279.

Flexas, J., Bota, J., Galmes, J., Medrano, H., Ribas-Carbo, M. 2006. Keeping a positive carbon balance under adverse conditions: responses of photosynthesis and respiration to water stress. Physiologia Plantarum 127:343-352.

Griffith, S. 1992. Changes in post-anthesis assimilates in stem and spike components of Italian Ryegrass (Lolium multiflorum Lam.). I Water soluble carbohydrates. Ann. Bot. 69:243-248.

Guoth, A., Tari, I., Galle, A., Csizsar, J., Horvath, F., Pecsvaradi, A., Cseuz, L., Erdei, L. 2009. Chlorophyll a flourescence induction parameters of flag leaves characterizes genotypes and not the drought tolerance of wheat during grain filling under water deficit. Acta Biologica Szegediensis 53:1-7.

Hunt, R. 1978. Plant growth analysis. In: Arnold, E. (ed.), Studies in Biology. London, UK. 96:26-38.

Kage, H., Kochler, M., Stützel, H. 2004. Root growth and dry matter partitioning of cauliflower under drought stress conditions: measurement and simulation. Eur. J. Agron. 20:379-394.

Kong, L., Wang, F., Feng, B., Li, Sh., Si, J., Zhang, B. 2010. The structural and photosynthetic charactersitics of the exposed peduncle of wheat (Triticum aestivum L.): an important photosynthate source for grain-filling. BMC Plant Biology 10:141.

Liu, E.K., Mei, X.R., Yan, C.R., Gong, D.Z., Zhang, Y.Q. 2016. Effects of water stress on photosynthetic characteristics, dry matter translocation and WUE in two winter wheat genotypes. Agricult. Water Management 167:75-85.

Ma, S.C., Duan, A.W., Wang, R., Guan, Z.M., Yang, S.J., Ma, S.T., Shao, Y. 2015. Root-sourced signal and photosynthetic traits dry matter accumulation and remobilization, and yield stability in winter wheat as affected by regulated deficit irrigation. Agricult. Water Management 148:123-129.

Man, J., Yu, S., Yu, Z., Zhang, Y. 2015. Dry matter production, photosynthesis of flag leaves and water use in winter wheat are affected by supplemental irrigation in the Huang-Huai-Hai plain of China. PLOS One, 10(9); e0137274. DOI: 10.1371/journal.pone.0137274.

Mekliche, A., Hanifi, M.L., Aidaoui, A., Gate, Ph., Bouthier, A., Monneveux, Ph. 2015. Grain yield and its components study and their association with normalized difference vegetation index (NDVI) under terminal water deficit and well-irrigated conditions in wheat (Triticum durum Desf. and Triticum aestivum L.). African J. of Biotechnol. 14:2142-2148.

Miller, T. 1992. Growth stages of wheat: Identification and understanding improve crop management. Better Crops 76:12-17.

Murata, Y. 1981. Dependence of the potential productivity and efficiency in solar energy utilization on leaf photosynthetic capacity in crop species. Japan. J. Crop Sci. 50:223-232.

Olsovska, K., Kovar, M., Brestic, M., Zivcak, M., Slamka, P., Shao, H.B. 2016. Genotypical identifying wheat mesophyll conductance regulation under progressive drought stress. Frontiers in Plant Sci. 7:1111.

Plaut, Z., Butow, B.J., Blumenthal, C.S., Wrigley, C.W. 2004. Transport of dry matter into developing wheat kernels and its contribution to grain yield under post-anthesis water deficit and elevated temperature. Field Crops Res. 86:185-198.

Peeva, V., Cornic, G. 2009. Leaf photosynthesis of Haberlea rhodopensis before and during drought. Environ. Exp. Bot. 65:310-318.

Quarrie, S., Stojanovic, J., Pekic, S. 1999. Improving drought resistance in small grained cereals: A case study, progress and prospects. Plant Growth Regul. 29:1-21.

Rawson, H.M., Evans, L.T. 1971. The contribution of stem reserves to grain development in a range of wheat cultivars of different height. Aust. J. Agricult. Res. 22:851-863.

Reynolds, M., Calderini, D., Condon, A., Vargas, M. 2007. Association of source/sink traits with yield, biomass and radiation use efficiency among random sister lines from three wheat crosses in a high-yield environment. J. Agric. Sci. 145:3-16.

Reynolds, M.P., Skovmand, B., Trethowan, R., Pfeiffer, W. 2000. Evaluating a conceptual model for drought tolerance. In: Ribaut, J.M., Poland, D. (eds), Molecular Approaches for Genetic Improvement of Cereals for Stable Production in Water-Limited Environments, CIMMYT. Mexico. pp. 49-53.

Richards, R. 2000. Selectable traits to increase crop photosynthesis and yield of grain crops. J. Exp. Bot. 51:447-458. 
Saeidi, M., Moradi, F., Jalali, H.S. 2012. The effect of post-anthesis source limitation treatments on wheat cultivars under water deficit. Aust. J. Crop Sci. 6:1179-1187.

Sharkey, T.D., Laporate, M.M., Micallef, B.J., Shewmaker, C.K., Oakes, J.W. 1995. Sucrose synthesis, temperature, and plant yield. In: Mathis, P. (ed.), From Light to Biosphere. Kluwer Academic Publishers. Dordrecht, The Netherlands pp. 635-640.

Siddique, M.R.B., Hamid, A., Islam, M.S. 1999. Drought stress effects on photosynthetic rate and leaf gad exchange of wheat. Bot. Bull. Acad. Sin. 40:141-145.

Wang, Z., Wei, A., Zheng, D. 2001. Photosynthetic characteristics of non-leaf organs of winter wheat cultivars differing in ear type and their relationship with grain mass per ear. Photosynthetica 39:239-244.

Yang, J., Zhang, J., Wang, Z., Zhu, Q., Liu, L. 2001. Water deficit-induced senescence and its relationship to the remobilization of pre-stored carbon in wheat during grain filling. Agron. J. 93:196-206.

Zhou, Y., Lam, H.M., Zhang, J. 2007. Inhibition of photosynthesis and energy dissipation induced by water and high light stresses in rice. J. Exp. Bot. 58:1207-1217.

\section{Electronic Supplementary Material (ESM)}

Electronic Supplementary Material (ESM) associated with this article can be found at the website of CRC at http://www.akademiai.com/content/120427/

Electronic supplementary Table S1. Effect of drought stress on gas exchange parameters at anthesis. Each value represents mean $\pm \mathrm{SD}$ of $7-9$ replicates

Electronic supplementary Table S2. Correlation coefficients between traits (2013-2014 growing season)

Electronic supplementary Table S3. Correlation coefficients between traits (2014-2015 growing season)

Electronic supplementary Figure S1. Regression relation between photosynthesis rate and growth rate of genotypes

Electronic supplementary Figure S2. Effect of water stress on leaf dry mass per stem (2014). Each value represents mean of 5-7 replicates

Electronic supplementary Figure S3. Effect of water stress on leaf dry mass per stem (2015). Each value represents mean of 5-7 replicates

Electronic supplementary Figure S4. Effects of water stress on stem dry mass (2014). Each value represents mean of 5-7 replicates

Electronic supplementary Figure S5. Effect of water stress on stem dry mass (2015). Each value represents mean of 5-7 replicates

Electronic supplementary Figure S6. Effect of water stress on spike dry mass (2014). Each value represents mean of 5-7 replicates

Electronic supplementary Figure S7. Effect of water stress on spike dry mass (2015). Each value represents mean of 5-7 replicates

Electronic supplementary Figure S8. Effect of drought stress on grain yield of wheat genotypes. Each value represents mean of 3 replicates 